\title{
Quality of life among menopausal women
}

\author{
Hoda A. E. Mohamed ${ }^{1,4}$, Sahar M. Lamadah ${ }^{2,4}$, Luma Gh. Al. Zamil La $^{3,4}$
}

\begin{abstract}
${ }^{1}$ Assistance Professor of Obstetrical and Gynecological Nursing, Faculty of Nursing, El-Minia University, Egypt ${ }^{2}$ Lecturer of Obstetrical and Gynecological Nursing, Faculty of Nursing, Alexandria University, Alexandria, Egypt ${ }^{3}$ Speech Language Pathologist, Jordan University, Bachelor's Degree, Faculty of Nursing, Jordan University Scientific \& Technology, Jordan

${ }^{4}$ Faculty of Nursing, Umm Al Qura University, Al Abdya, K S A
\end{abstract}

Received: 7 June 2014

Accepted: 1 July 2014

*Correspondence:

Dr. Sahar M. Lamadah,

E-mail: dr.saharlamadah@yahoo.com

(C) 2014 Mohamed HA et al. This is an open-access article distributed under the terms of the Creative Commons Attribution Non-Commercial License, which permits unrestricted non-commercial use, distribution, and reproduction in any medium, provided the original work is properly cited.

\section{ABSTRACT}

Background: The transition through menopause is a life event that can profoundly affect quality of life. More than $80 \%$ of women report physical and psychological symptoms that commonly accompany menopause, with varying degree of severity and life disruption. The aim of this study was to assess the menopausal related symptoms and their impact on the women's quality of life. Research questions: Are the menopausal symptoms impacts on the women's quality of life?

Methods: A descriptive design was used. A convenient sample composed of 90 women at range of age between 4060 years was recruited from gynecological department. An interviewing sheet was designed by the researchers and menopause specific quality of life questionnaire were used to collect the data.

Results: The present study showed that the most severe symptoms of vasomotor, psychosocial, physical and sexual domains were, hot flushes $(29 \%)$, experiencing poor memory $(48.3 \%)$, being dissatisfied with their personal life (44.8\%), Low backache $(41.9 \%)$, and change in sexual desire $(36.8 \%)$. The overall scores of menopausal quality of life for each domain are indicated that the highest mean score in sexual domain $(3.19 \pm 1.99)$, followed by psychosocial $(2.94 \pm 1.45)$.

Conclusions: It can be concluded that the most severe symptoms of vasomotor, psychosocial, physical and sexual domains were, hot flushes, poor memory, dissatisfaction with personal life, low backache, and change in sexual desire. While the mean scores of each domain suggest that menopausal symptoms were associated with decrease in women quality of life.

Keywords: Menopausal symptoms, Quality of life

\section{INTRODUCTION}

Today, with increasing life expectancy and life span, women spend one-third of their lifetime after menopause. ${ }^{1,2}$ Menopause is an adaptation process during which women go through a new biological state. This process is accompanied by many biological and psychosocial changes. $^{3}$ Menopause is a normal physiological process which is characterized by the permanent cessation of menses in women as a result of reduced ovarian hormone secretion usually between the ages of 45 and 55 years. During this period women can experience many symptoms including hot flashes, night sweats, sleep and mood disorders, impaired memory, lack of concentration, nervousness, depression, insomnia, bone and joint complaints, and reduction of muscle mass. The duration, severity, and impact of these symptoms vary extremely from person to person, and population to population. Some women have severe symptoms that greatly affect their personal and social functioning, and 
quality of life. ${ }^{4}$ Vasomotor symptoms, are common physical conditions experienced by midlife women in the transition through menopause and early post menopause. , $^{5,}$

Psychological symptoms frequently associated with menopause include fatigue, irritability, and anxiety. Some symptoms associated with changing hormone levels are directly linked with estrogen depletion. Hot flashes, night sweats, and vaginal atrophy resulting in vaginal dryness are correlated with changing levels of sex hormones. Other symptoms, such as sleep disturbances, fatigue, anxiety, and weight gain, although common to the experience of menopause, are multi factorial in cause and occur in non-postmenopausal women as well. ${ }^{8}$ Studies find that most women experience at least one or more of these symptoms as they transition through the postmenopausal stage of life. ${ }^{5}$

The mean age of the menopause in Egypt is 46.7 years, which is low compared to many countries, but this age has been rising in the past few years in the west, probably because of the different socio-cultural attitude towards the menopause in different communities. The western woman attitude towards the menopause is generally positive and about one third of them considers the menopause as a normal physiological change. Nevertheless, the Egyptian women need an awareness campaign about menopause in order to educate them about this important stage of their lives. ${ }^{9}$

Despite a majority of women experiencing multiple symptoms, the literature still presents a gap on whether clusters of symptoms consistently occur and what these symptoms have on quality of life. ${ }^{5}$ Study in Saudi Arabia showed that 'hot flashes' and 'sweating' (68.5\%), 'vaginal dryness' (37.3\%) and 'sexual problems' (30.7\%) were the most common symptoms among menopausal women. In addition, the most severe symptoms were hot flashes and excessive sweating. ${ }^{10}$ The frequency of symptoms can vary based on epidemiological characteristics of the population and the assessment tools used. ${ }^{11}$ The effect of menopausal transition on women's lives is complex and includes changes in physical health, psychosomatic domains, and personal life. Health-related quality of life may be severely compromised in women with vasomotor symptoms. Up to $40 \%$ of women in Sweden experience vasomotor symptoms until the age of 64 years. $^{12}$

Quality of life is a broad, multidimensional concept that lacks a precise definition in the medical literature. According to the World Health Organization, quality of life is individuals' perception of their position in life in the context of the culture and value systems in which they live and in relation to their goals, expectations, standards, and concerns. ${ }^{13}$ Quality of life tends to decline in midlife women, and there is a need to determine what role, if any, symptoms commonly associated with the transition to menopause and early postmenopausal play in this phenomenon. ${ }^{14,15}$ Quality of life is an important outcome measure of health care, and understanding the impact of menopause on quality of life is a critically important part of the care of symptomatic postmenopausal women. ${ }^{16}$ The study of quality of life in the post-menopausal women has become an essential component in clinical practices. Most studies on quality of life of postmenopausal women were conducted in developed countries with different socio cultural realities, which may influence not only the perception of quality of life but also the experience of menopausal symptoms. Very little information exists about quality of life of postmenopausal women in developing countries. ${ }^{17}$

\section{Significance of the study}

The transition through menopause is a life event that can profoundly affect quality of life. More than $80 \%$ of women report physical and psychological symptoms that commonly accompany menopause, with varying degrees of severity and life disruption. ${ }^{1}$ Few empirical studies, however, have examined the interrelated nature of symptoms associated with the menopausal transition and early postmenopausal and the effects of those symptom groups on quality of life. ${ }^{14}$ Maintaining good physical functioning with age is a vital component of independence in later life. ${ }^{18-20}$

Identifying characteristics associated with poor physical functioning could contribute to prevention and management strategies that help older women to maintain their independence and also therefore their quality of life. Health-care providers play a more visible and instrumental role in continuously assessing menopausal women's needs as well as to implement appropriate health educational programs and to develop a new way to meet their demands. ${ }^{17}$

\section{Aim of study}

The aim of this study was to assess the menopausal related symptoms and their impact on the women's quality of life.

\section{Research questions}

Are the menopausal symptoms impacts on the women's quality of life?

\section{METHODS}

\section{Research design}

Descriptive design was used in this study

\section{Setting}

The study was conducted in Gynecological department at maternity and children's hospital in Makkah Al Mukkaramah. 


\section{Subjects}

A convenient sample of 90 women at menopausal stages was recruited in the study according to the following criteria:

- Mentally oriented.

- Women's age between 40 to 60 years.

- Don't use hormonal replacement therapy.

- $\quad$ Able to read and write.

- Free from medical conditions like diabetes, hypertension, cardiac disease and thyroid disorder.

\section{Tools}

Two tools were used to collect the necessary data

I. Interviewing sheet: was designed by the researchers and it includes data about women's socio demographic data and menstrual history etc...

II. Menopause specific quality of life questionnaire (MENQOL): It is a self-report measure assessing the presence and severity of menopausal symptoms and the degree to which they adversely affect women's life designed by (Hilditch JR, Lewis J). ${ }^{21}$ It consists of 29 items divided into four domains: vasomotor (three items), psychosocial (seven items), physical (16 items) and sexual (three items), the vasomotor domain assesses hot flushes, night sweats, and sweating. The psychosocial domain evaluates the psychological well-being of the individual by including items regarding anxiousness, memory, and feeling "blue". The physical domain assesses items such as flatulence, bloating, pain, tiredness, sleeping, energy and weight gain. The sexual domain includes items related to changes in sexual desire, vaginal dryness, and intimacy.

The systematic scoring for each of the four MENQOL domains is identical. The seven-point Likert scale used during the administration of the MENQOL is converted for scoring and data analysis. For each of the 29 items, this seven-point Likert scale is converted to an eight point scale, ranging from 1 to 8 . A "one" is equivalent to a woman responding "no", indicating she has not experienced this symptom in the past month. A "two" indicates that the woman experienced the symptom, but it was not at all bothersome. Scores "three" through "eight" indicate increasing levels of bother experienced from the symptom, and correspond to the " 1 " though " 6 ". The score by domain is the mean of the converted item scores forming that domain and ranges from 1-8. Severities of menopause symptoms scoring system as the following, Score range from 2-4 consider mild, score range from 5-6 moderate, and score range from 7-8 severe symptoms.

\section{Validity and reliability}

To measure content validity of the tools, the researchers assure that items of an instrument adequately represent what are supposed to measure by presented it to 3 experts from obstetrics and Gynecology nursing) who conducted face and content validity of all item. All recommended modifications were performed. Also using Menopause Specific Quality Of Life Questionnaire (MENQOL) is considering standard evidence support validity of the tools. The reliability of tool was tested by Alpha Cronbach test. Its result was 0.721 which indicates an accepted reliability of the tool.

\section{Administrative design}

Needed permissions were obtained through appropriate channels. An official permission was directed from the dean of the faculty of nursing at Umm Al-Qura University to the manager of the selected hospital requesting his approval for data collection.

\section{Pilot study}

To assess the clarity, reliability and applicability of the study tools used in the study for data collection, a pilot study was conducted with a representative sample of ten women. The results of the pilot study helped in the necessary modifications of the tools as omission of unneeded or repeated questions and adding missed questions. The women included in the pilot study were excluded from the study subjects.

\section{Field work}

The researchers attended the gynecological ward of the studied setting two days per week, from 9.00 a.m. to 1.00 p.m. The study was conducted from the beginning of October to December 2013. The researchers introduced themselves and briefly explained the purpose of the study to the approached women who met the criteria for inclusion in the study. All women were informed that participation is voluntary. Oral acceptance of women to participate in the study was obtained. Data collection was carried out through interviewing with women. Time consumed for each interview ranges from 30 to 45 minutes with each woman using the previously mentioned tool. The researchers collected data related to socio demographic data, menstruation status, and menopausal symptoms.

Menopausal status was determined based on the reported length of time since last menstrual period. Women with slight change in the length of cycle were classified as Menopause Transition (MT). While women whose last menstrual period occurred 12 months or more ago were categorized as Post Menopause (PM). The experience of symptoms, is tested by Menopause Specific Quality Of Life (MENQOL) questionnaire. Menopause Specific Quality Of Life (MENQOL) questionnaire 
consists of 29 items. All items followed the same format. Each woman was asked whether she experienced the symptoms in the previous six months, if answer was no she was asked next item and if answer was yes she was asked to indicate how bothered she had been by the symptoms on a 7 point scale ranging from $0=$ not at all bothered to 6 extremely bothered. For analysis score becomes 1 for "No", 2 for "Yes" through to 8 for "Yes (Extremely bothered)". Grading the severity of the symptoms as; mild, moderate or severe calculated as score from 2-4 (mild), scores from 5-6 (moderate) and from 7-8 (severe). The tools of data collection were translated into Arabic by the researchers, tested and verified by bilingual persons.

\section{Ethical consideration}

Informed consent was obtained from each participant. The significant and purpose of the study was explained to women. Confidentiality of any obtained information was ensured.

\section{Statistical design}

Data was collected, coded, tabulated and analyzed, using the SPSS computer application for statistical analysis. Descriptive statistics was used to calculate percentages, frequencies, Mean and standard deviations, Chi square $\left(\mathrm{X}^{2}\right)$, T test are used to estimate the statistical significant differences. A significant $\mathrm{P}$ value will be considered when $\mathrm{P}$ less than 0.05 and it will be considered highly significant when $\mathrm{P}$ value less than or equal 0.01 .

\section{RESULTS}

The results of this study are presented under the following three heading demographic characteristics of the women, menopausal symptoms, and quality of life scores among menopausal women.

\section{Socio demographic characteristics of the women}

As shown in Figure 1, less than two third (62.0\%) of the women's age ranged between $40-<50$ years. As presented in Figure 2, the percentage of women who received university education was $(53.0 \%)$, while $(11.0 \%)$ of the women had intermediate education. In relation to occupation $51.0 \%$ of the women were housewives and $49.0 \%$ were working (Figure 3 ).

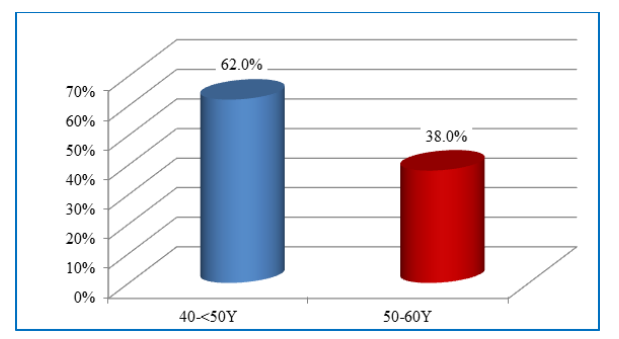

Figure 1: Distribution of the women by their age.

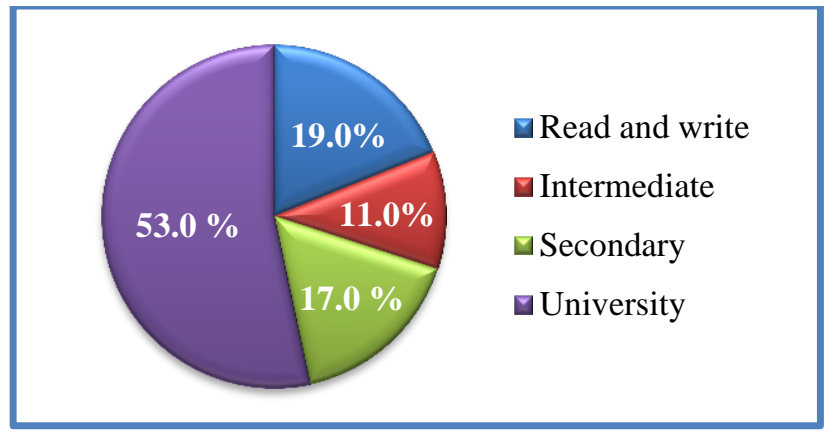

Figure 2: Distribution of the women by their educational level.

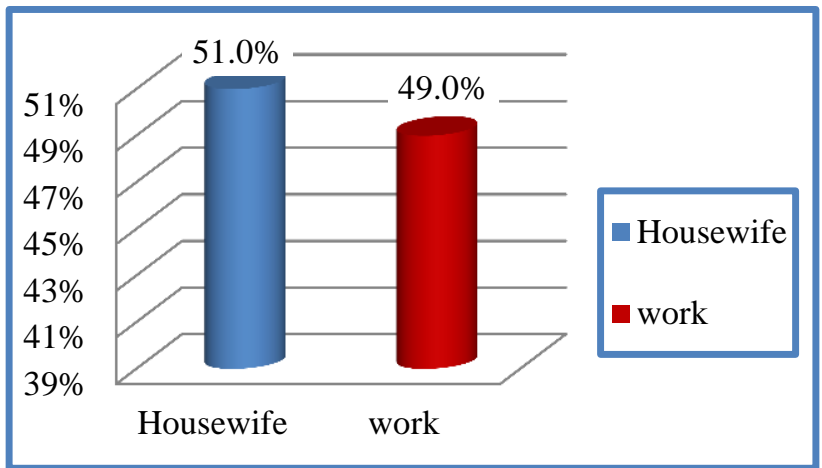

Figure 3: Distribution of the women by their occupation.

Figure 4 illustrates menopausal stages of the women; it was found that $48(53.3 \%)$ of women at post-menopausal stage while $42(47.7 \%)$ of them at menopausal transition stage.

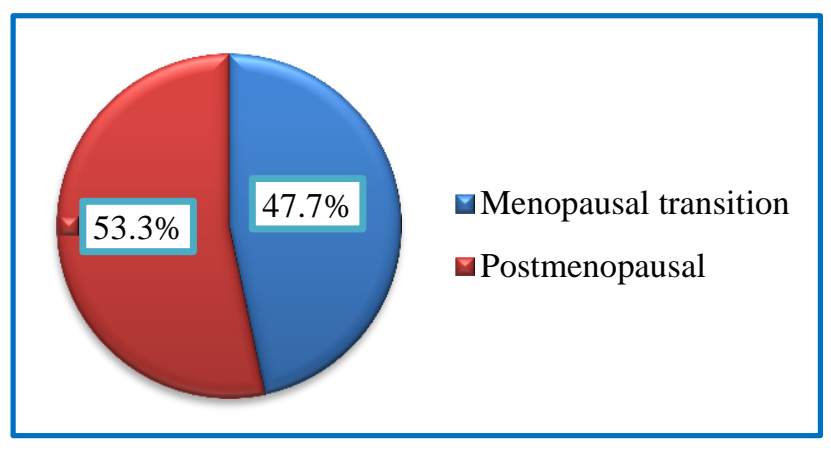

Figure 4: Distribution of the women by their menopausal stages.

\section{Menopausal symptoms}

Table 1 illustrated the severity of the menopausal symptoms among the studied subjects. It can be observed that, the most severe symptoms of vasomotor, psychosocial, physical and sexual domains were, hot flushes $(29.0 \%)$, experiencing poor memory $(48.3 \%)$, being dissatisfied with their personal life $(44.8 \%)$, Low backache $(41.9 \%)$, and change in their sexual desire $(36.8 \%)$, while the mild symptoms in these domains were 
night sweats $(54.2 \%)$, sweating $(56.3 \%)$, feeling anxious or nervous $(51.7 \%)$, flatulence (wind) or gas pains
(68.4\%), difficulty sleeping (67.5\%), Increased facial hair $(67.7 \%)$, and avoiding intimacy $(60.5 \%)$.

Table 1: Distribution of the women regarding to severity of menopausal symptoms.

\begin{tabular}{|c|c|c|c|c|c|c|}
\hline \multirow{2}{*}{ Symptoms* } & \multicolumn{2}{|c|}{ Mild } & \multicolumn{2}{|c|}{ Moderate } & \multicolumn{2}{|c|}{ Severe } \\
\hline & No. & $\%$ & No. & $\%$ & No. & $\%$ \\
\hline \multicolumn{7}{|l|}{ Vasomotor } \\
\hline Hot flushes & 20 & 41.7 & 14 & 29.2 & 14 & 29.2 \\
\hline Night sweats & 26 & 54.2 & 13 & 27.1 & 9 & 18.8 \\
\hline Sweating & 27 & 56.3 & 14 & 29.2 & 7 & 14.6 \\
\hline \multicolumn{7}{|l|}{ Psychosocial } \\
\hline Being dissatisfied with my personal life & 12 & 41.4 & 4 & 13.8 & 13 & 44.8 \\
\hline Feeling anxious or nervous & 15 & 51.7 & 3 & 10.3 & 11 & 37.9 \\
\hline Experiencing poor memory & 12 & 41.4 & 3 & 10.3 & 14 & 48.3 \\
\hline Accomplishing less than I used to & 12 & 41.4 & 7 & 24.1 & 10 & 34.5 \\
\hline Feeling depressed, down or blue & 12 & 41.4 & 6 & 20.7 & 11 & 37.9 \\
\hline Being impatient with other people & 13 & 44.8 & 4 & 13.8 & 12 & 41.4 \\
\hline Feelings of wanting to be alone & 13 & 41.4 & 4 & 13.8 & 12 & 41.4 \\
\hline \multicolumn{7}{|l|}{ Physical } \\
\hline Flatulence (wind) or gas pains & 39 & 68.4 & 3 & 6.3 & 15 & 26.3 \\
\hline Aching in muscle \& joints & 44 & 59.5 & 7 & 9.6 & 23 & 31.1 \\
\hline Feeling tired or worn out & 40 & 55.6 & 9 & 12.5 & 23 & 31.9 \\
\hline Difficulty sleeping & 35 & 67.5 & 4 & 7.7 & 13 & 25 \\
\hline Aches in back of neck or head & 44 & 62.0 & 11 & 12.2 & 16 & 17.8 \\
\hline Decrease in physical Strength & 15 & 48.4 & 6 & 19.4 & 10 & 32.3 \\
\hline Decrease in stamina & 17 & 54.8 & 4 & 12.9 & 10 & 32.3 \\
\hline Feeling a lack of energy & 15 & 48.4 & 7 & 22.6 & 9 & 29 \\
\hline Drying skin & 19 & 61.3 & 6 & 19.4 & 6 & 19.4 \\
\hline Weight gain & 13 & 41.9 & 7 & 22.6 & 11 & 35.5 \\
\hline Increased facial hair & 21 & 67.7 & 8 & 25.8 & 2 & 6.5 \\
\hline Changes in appearance, texture or tone of your skin & 16 & 51.6 & 10 & 32.3 & 5 & 16.1 \\
\hline Feeling bloated & 10 & 32.3 & 14 & 45.2 & 7 & 22.6 \\
\hline Low backache & 12 & 38.7 & 6 & 19.4 & 13 & 41.9 \\
\hline Frequent urination & 11 & 35.5 & 12 & 38.7 & 8 & 25.8 \\
\hline Involuntary urination when laughing or coughing & 12 & 38.7 & 11 & 35.5 & 8 & 25.8 \\
\hline \multicolumn{7}{|l|}{ Sexual } \\
\hline Change in your sexual desire & 23 & 60.5 & 1 & 2.6 & 14 & 36.8 \\
\hline Vaginal dryness during intercourse & 21 & 55.3 & 10 & 26.3 & 7 & 18.4 \\
\hline Avoiding intimacy & 23 & 60.5 & 5 & 13.2 & 10 & 26.3 \\
\hline
\end{tabular}

*Multiple responses

In relation to the relationship between the severity of symptoms and menopausal stage, Table 2 showed that $(29.16 \%)$ of postmenopausal women experienced severe symptoms as compared to only $(8.33 \%)$ of women in menopausal transition. There was a statistically significant difference between the severity of menopausal symptoms and menopausal stage $\left(\mathrm{X}^{2}=9.489\right.$ at $\mathrm{P}$ $<0.009)$.

Table 2: Relationship between the severity of menopausal symptoms and menopausal stage.

\begin{tabular}{|c|c|c|c|c|c|c|c|c|c|}
\hline \multirow{2}{*}{ Symptoms } & \multicolumn{2}{|c|}{ Mild } & \multicolumn{2}{|c|}{ Moderate } & \multicolumn{2}{|c|}{ Severe } & \multirow{2}{*}{$\begin{array}{l}\text { Total } \\
\text { No }(\%)\end{array}$} & \multirow{2}{*}{$\mathbf{X}$} & \multirow{2}{*}{ P value } \\
\hline & No. & $\%$ & No. & $\%$ & No. & $\%$ & & & \\
\hline \multicolumn{10}{|l|}{ *Menopausal } \\
\hline Menopausal transition & 12 & 25 & 7 & 14.5 & 4 & 8.33 & $23(47.9)$ & \multirow{2}{*}{9.489} & \multirow{2}{*}{0.009} \\
\hline Post-menopausal & 4 & 8.33 & 7 & 14.5 & 14 & 29.16 & $25(52.1)$ & & \\
\hline
\end{tabular}

*Scores ranged from 2-8. 
Table 3: Relationship between the severity of menopausal symptoms and socio-demographic characteristics.

\begin{tabular}{|c|c|c|c|c|c|c|c|c|c|}
\hline \multirow{2}{*}{ Symptoms } & \multicolumn{2}{|c|}{ Mild } & \multicolumn{2}{|c|}{ Moderate } & \multicolumn{2}{|c|}{ Severe } & \multirow{2}{*}{$\begin{array}{l}\text { Total } \\
\text { No }(\%)\end{array}$} & \multirow{2}{*}{$\mathbf{X}$} & \multirow{2}{*}{$\begin{array}{l}P \\
\text { value }\end{array}$} \\
\hline & No. & $\%$ & No. & $\%$ & No. & $\%$ & & & \\
\hline \multicolumn{10}{|l|}{ Age } \\
\hline $40-<50$ & 10 & 20.83 & 11 & 22.91 & 6 & 12.5 & $27(56.3)$ & \multirow{2}{*}{6.930} & \multirow{2}{*}{0.031} \\
\hline $50-65$ & 6 & 12.5 & 3 & 6.25 & 12 & 2 & $21(43.7)$ & & \\
\hline \multicolumn{10}{|l|}{ Education } \\
\hline Read and write & 3 & 6.25 & 1 & 2.08 & 2 & 4.16 & $6(12.5)$ & \multirow{4}{*}{8.107} & \multirow{4}{*}{ N.S } \\
\hline Primary/intermediate & 2 & 4.16 & 2 & 4.16 & 3 & 6.25 & $7(14.5)$ & & \\
\hline Secondary & 6 & 12.5 & 2 & 4.16 & 1 & 2.08 & $9(18.8)$ & & \\
\hline University & 5 & 10.41 & 9 & 18.75 & 12 & 25 & $26(54.2)$ & & \\
\hline \multicolumn{10}{|l|}{ Occupation } \\
\hline Working & 6 & 12.5 & 5 & 10.5 & 10 & 20.8 & $21(43.7)$ & \multirow{2}{*}{1.641} & \multirow{2}{*}{ N.S } \\
\hline Housewives & 10 & 20.8 & 9 & 18.8 & 8 & 16.66 & $27(56.3)$ & & \\
\hline
\end{tabular}

As regards to the relationship between the severity of menopausal symptoms and socio demographic characteristics, Table 3 showed that there was a statistically significant difference between the severity of menopausal symptoms and current age $\left(\mathrm{X}^{2}=6.93\right.$ at $\mathrm{P}=$ $0.031)$.

However, there were no significant differences between; severity of menopausal symptoms and level of education and occupation.

\section{Quality of life scores among menopausal women}

Table 4 indicated that the highest mean scores of symptoms in vasomotor, psychosocial, physical and sexual domains were, hot flush $(3.27 \pm 2.23)$, Feeling anxious or nervous $(3.5 \pm 2.25)$, experiencing poor memory $(3.38 \pm 2.10)$, aching in muscle \& joint $(4.88 \pm$ $2.20)$, Feeling tired or worn out $(4.62 \pm 2.32)$, low backache $(4.55 \pm 2.25)$, change in sexual desire (3.61 \pm $2.43)$ and avoiding intimacy $(3.20 \pm 2.50)$ respectively.

Table 5 illustrated the overall scores of menopausal quality of life for each MENQOL domain. It was observed that the highest mean score in sexual domain $(3.19 \pm 1.99)$, followed by psychosocial $(2.94 \pm 1.45)$ then vasomotor $(2.55 \pm 1.53)$ and finally physical symptoms $(2.28 \pm 0.749)$.

As regard to the four domain scores of menopausal status. Results of the study showed that the mean scores of physical domain and vasomotor domain were $(2.48 \pm$ $0.75)$ and $(2.86 \pm 1.56)$ in Post-Menopausal (PM) group as compared to $(2.14 \pm 0.72)$ and $(2.32 \pm 1.48)$ in menopausal transition groups respectively. There were statistically significant differences between the two groups $(\mathrm{t}=2.11$ at $\mathrm{P}<0.03)$ and $(\mathrm{t}=1.66$ at $\mathrm{P}<0.09)$ respectively. While, there is no statistically significance difference between the two groups as regarding to psychosocial and sexual domains (Table 6).
Table 4: Scores of MENQOL items.

\begin{tabular}{|ll|}
\hline Symptoms & *Scores \\
\hline Vasomotor & \\
\hline Hot flushes & $\mathbf{3 . 2 7} \pm 2.23$ \\
\hline Night sweats & $2.28 \pm 1.93$ \\
\hline Sweating & $2.16 \pm 1.93$ \\
\hline Psychosocial & \\
\hline Being dissatisfied with my personal life & $2.24 \pm 2.13$ \\
\hline Feeling anxious or nervous & $\mathbf{3 . 5} \pm 2.25$ \\
\hline Experiencing poor memory & $\mathbf{3 . 3 8} \pm 2.10$ \\
\hline Accomplishing less than I used to & $3.16 \pm 2.08$ \\
\hline Feeling depressed, down or blue & $2.6 \pm 2.22$ \\
\hline Being impatient with other people & $2.94 \pm 2.28$ \\
\hline Feelings of wanting to be alone & $2.76 \pm 2.43$ \\
\hline Physical & $3.62 \pm 2.33$ \\
\hline Flatulence (wind)or gas pains & $\mathbf{4 . 8 8} \pm 2.20$ \\
\hline Aching in muscle \& joints & $\mathbf{4 . 6 2} \pm 2.32$ \\
\hline Feeling tired or worn out & $3.43 \pm 2.38$ \\
\hline Difficulty sleeping & $4.27 \pm 2.17$ \\
\hline Aches in back of neck or head & $4.23 \pm 2.04$ \\
\hline Decrease in physical Strength & $3.87 \pm 2.15$ \\
\hline Decrease in stamina & $4.04 \pm 2.08$ \\
\hline Feeling a lack of energy & $4.07 \pm 2.31$ \\
\hline Drying skin & $3.18 \pm 2.45$ \\
\hline Weight gain & $2.12 \pm 1.75$ \\
\hline Increased facial hair & $2.87 \pm 2.09$ \\
\hline $\begin{array}{l}\text { Changes in appearance, texture or tone } \\
\text { of your skin }\end{array}$ & $3.25 \pm 2.23$ \\
\hline Feeling bloated & $\mathbf{4 . 5 5} \pm 2.25$ \\
\hline Low backache & $3.60 \pm 2.37$ \\
\hline Frequent urination & $2.62 \pm 2.09$ \\
\hline $\begin{array}{l}\text { Involuntary urination when laughing or } \\
\text { coughing }\end{array}$ & $\mathbf{3 . 6 1} \pm 2.43$ \\
\hline Sexual & $\mathbf{3 . 2 0} \pm 2.50$ \\
\hline Change in your sexual desire & \\
\hline Vaginal dryness during Intercourse & \\
\hline Avoiding intimacy & \\
\hline
\end{tabular}


Table 5: Score for each MENQOL domain.

\begin{tabular}{|ll|}
\hline Domain & Total scores* \\
\hline Vasomotor & $2.55 \pm 1.53$ \\
\hline Psychosocial & $2.94 \pm 1.45$ \\
\hline Physical & $2.28 \pm 0.749$ \\
\hline Sexual & $3.19 \pm 1.99$ \\
\hline
\end{tabular}

*MENQOL, menopause-specific quality of life questionnaire; Scores ranged from 1-8

Table 6: Mean distribution for each MENQOL domain scores by menopausal stage.

\begin{tabular}{|c|c|c|c|c|}
\hline \multirow[t]{2}{*}{ Domain } & $\begin{array}{l}\text { Menopausal } \\
\text { transition } \\
\text { NO (52) }\end{array}$ & $\begin{array}{l}\text { Post- } \\
\text { menopausal } \\
\text { NO (38) }\end{array}$ & \multirow[t]{2}{*}{$\mathrm{t}$} & \multirow[t]{2}{*}{$\begin{array}{l}\mathbf{P} \\
\text { value }\end{array}$} \\
\hline & Mean* \pm SD & Mean* \pm SD & & \\
\hline Vasomotor & $2.32 \pm 1.48$ & $2.86 \pm 1.56$ & 1.66 & 0.09 \\
\hline $\begin{array}{l}\text { Psycho- } \\
\text { social }\end{array}$ & $2.77 \pm 1.50$ & $3.17 \pm 1.36$ & 1.30 & 0.197 \\
\hline Physical & $2.14 \pm 0.72$ & $2.48 \pm 0.75$ & 2.11 & 0.03 \\
\hline Sexual & $2.92 \pm 2.01$ & $3.55 \pm 1.92$ & 1.47 & NS \\
\hline
\end{tabular}

*MENQOL, menopause-specific quality of life questionnaire; Scores ranged from 1-8

\section{DISCUSSION}

Menopause is a transitional period that every woman goes through if she lives beyond the age of 52 years. The individual response to menopause and estrogen deficiency varies considerably due to genetic, cultural, lifestyle, socioeconomic, education, and dietary factors. Menopause has emerged as a prominent issue in the women's health. Maintaining optimal Quality Of Life (QOL) is a priority for women as they negotiate per menopause in partnership with the health professionals who provide their care. We evaluated the quality of life of woman with menopausal symptoms on MenQoL. It was developed in 1996, consisting of four domains: vasomotor, psychological, physical and sexual. ${ }^{8,21}$ The aim of the present study was to assess the menopausal related symptoms and their impact on the women's quality of life. Results of the current study answer the research question that menopausal symptoms impact on the quality of life of menopausal women.

As regards to the socio-demographic characteristics of the women, it was found that less than two thirds of the women's age ranged between $40-<50$ years old. This result is similar with the result of a study done by AlOleyat et al. (2010) who carried out a cross-sectional study on a sample of 233 Saudi women from 45 to 55 years old. ${ }^{10}$ Also in a study done by Gehad et al. (2010), the mean age of menopause was $46.35 \pm 4.8$ years in Egypt and mean age in Saudi Arabia was $49.9 \pm 2.23 .{ }^{22}$ In addition a study done by El Sabagh and Abd Allah (2012) indicated that women's age ranged from $40-70 .^{23}$ However, comparing our findings with the previous researches, ours still fall between the normal ranges of menopausal age.

In relation to the educational level, it was found that, more than half of the women had university education; this may reflect women's cooperation during conduction of the study. In addition, about one half of the women were housewives. This result is supported by the result of the study carried out by El Sabagh and Abd Allah (2012) who reported that $58.3 \%$ of women were housewives. ${ }^{23}$

As regards to the severity level of menopausal symptoms, the most severe symptoms of vasomotor, psychosocial, physical and sexual domains were, hot flushes, experiencing poor memory, being dissatisfied with their personal life, low backache, and change in their sexual desire, while the mild symptoms in these domains were night sweats, sweating, feeling anxious or nervous, flatulence, aches in back of neck or head, increased facial hair and avoiding intimacy. This may correlates with fluctuating levels of estrogen in the blood from premenopausal to postmenopausal period. These results are in accordance with the results of many studies reported that 'hot flashes' and 'sweating' were the most common and severe symptoms in menopausal women. $^{10,24}$ Results of Chim et al. (2002) in a Singaporean contradicted the results of the current study as they indicated that the frequency of hot flashes and night sweats was $17.6 \%$ and $8.9 \%$, respectively. ${ }^{25}$ Although in United States, African-American women reported hot flushes most frequently $(45.6 \%)$ followed by Hispanic (35.4\%), Caucasians (31.2\%), Chinese (20.5\%) and Japanese $(17.6 \%)$. Vasomotor symptoms are usually related to hormonal changes during menopause periods so this difference may have been due to genetic or sociocultural diversity and also differences in diet, especially the consumption of phytoestrogen foods. ${ }^{17}$

In addition, Jahanfar et al. (2006) contradicted the results of the present study as they reported that the most common and sever symptoms were found to be joint and muscle discomfort $(84.3 \%)$, followed by anxiety $(71.4 \%)$, physical and mental discomfort $(67.2 \%)$, hot flushes and sweating $(67.1 \%)$. These differences in frequencies of symptoms may be associated to differences of race, life style, culture, genetics and diet. ${ }^{26}$ In a study conducted by Waidyasekera et al. (2009) they reported that the joint and muscle discomfort, physical and mental exhaustion and hot flashes were the most prevalent menopausal symptoms. ${ }^{27}$ The results of current study are similar with Gharaibeh et al. (2010) who found that vasomotor symptoms were reported to have the highest scores as hot flushes and night sweating. ${ }^{28}$ In addition Ashrafi et al. $(2010)^{29}$ showed that night sweats, joint and muscle pain and hot flashes are the most common symptoms associated with menopause in Iranian women. These findings were also noted by Rahman et al. (2010) emphasized that the frequency of sexual problems, bladder problems and vaginal dryness were experienced 
mainly by premenopausal and postmenopausal group of women and it was also significant statistically in comparison to other menopausal status. ${ }^{30}$

The most prevalent psychosocial symptom in the present study was; poor memory that agrees with results of many studies, which indicated that the most common and severe symptom that was reported by women was poor memory. ${ }^{25,31,32}$ The results of present study contradicted with the results of a study done by Kalahroudi MA et al. (2012) who revealed that the most severe symptom was feeling anxious or nervous. ${ }^{33}$

Regarding physical domain, the present study showed that most of the women had a complaint of severe low backache while a study done by Kalahroudi MA et al. (2012) reported that feeling a lack of energy is the most complain and the most severe symptom was aching muscles or joints which contradicted our results. ${ }^{33}$ Similar findings were reported from China. ${ }^{34}$

Concerning sexual domains, current study results showed a 'change in sexual desire' was more severe in more than one third of women than other sexual related symptoms. A study done by Rostami A et al. (2003) contradicted our result as reported that the majority of women mentioned avoiding intimacy ${ }^{[35]}$. Also in Ecuadorian women this rate was $76.5 \%,{ }^{31}$ in Korean women the most common symptom was a change in sexual desire' that was severe in $27.1 \%$ of cases which is in line with the result of our study. ${ }^{36}$ Also, other investigators stated that the prevalence of 'change in sexual desire' was approximately $30.7 \% .^{10,37}$

Results of the present study showed that the severity of menopausal symptoms had a highly significant association with; menopausal age $(\mathrm{X}=6.93$ at $\mathrm{P}=0.031)$, however, there were no significant differences between; severity of menopausal symptoms and level of education and occupation. These results contradicted with the results of a study done by Kalahroudi MA et al. (2012) who reported that menopausal symptoms had a significant association with working status, educational level, exercise activity, exercise frequency and duration of menopause. ${ }^{33}$ Several studies have shown that women who had longer education, reported milder menopausal symptoms. ${ }^{32,38}$ But one study in Taiwan showed that educated women had more menopausal symptoms compared to less-educated women. ${ }^{35}$ Several studies have also shown the impact of working status on the severity of menopausal symptoms. ${ }^{2,25,39}$ Results of the present study were in agreement with the results of a study in Singapore which demonstrated that there was no association between level of education and menopausal symptoms. $^{25}$

As regard to menopausal stages, the current study showed that, less than one third of the postmenopausal women experienced severe symptoms because they had more time to adapt to the menopausal changes. This study finding is similar to studies done by Lee et al. ${ }^{36,38}$
According to quality of life scores among menopausal women, the current study revealed that the scores of physical domain were significantly more in postmenopausal (PM) group than menopausal transition MT group $(\mathrm{t}=2.11$ at $\mathrm{P}<0.03)$ and the mean scores of vasomotor domain were high in post-menopausal (2.86 \pm 1.56) as compared to $(2.32 \pm 1.48)$ in menopausal transition while there is no statistically significance difference as regarding to psychosocial and sexual domains. This results are accordance with Nisar $\mathrm{N}$ and Ahmed N (2009) who indicated that PM woman had significantly higher scores in physical domain then MT group $\mathrm{P}<0.002$, while the scores of psychological domain were significantly high in MT group than in PM (P <0.003). ${ }^{17}$ A study from Thailand showed many symptoms to be significantly related to MT stage (such as hot flushes, upset stomach, insomnia, and urinary symptoms) only night sweats and joint aches and pain were significantly associated with PM stage. ${ }^{17}$ Other studies reported that vasomotor complains were more prevalent in MT woman whereas psychological complains were more in PM women.

As regards to the overall scores of menopausal quality of life for each MENQOL domain, the results of current study showed that highest mean score in sexual domain, following by psychosocial then vasomotor and finally physical symptoms. Greenblum et al. (2012) ${ }^{8}$ concluded that the symptoms found to most significantly affect quality of life were sleep disturbances, fatigue, and anxiety.

\section{CONCLUSION}

The current study concluded that the most severe symptoms in vasomotor, psychosocial, physical and sexual domains were, hot flushes, experiencing poor memory, being dissatisfied with their personal life, low backache, and change in their sexual desire. The mean scores of physical and vasomotor domain were significantly more in Post-Menopausal (PM) group than menopausal transition MT group. While the mean scores of each domain suggest that menopausal symptoms were associated with decrease in women's quality of life.

\section{Recommendations}

\section{The current study recommended that}

1. Health care providers need to play a more visible and instrumental role in continuously assessing menopausal women's needs as well as implement appropriate health educational programs for women about the menopausal period and how to pass it safely.

2. Further research addressing women's health needs is also essential for improving the quality of life of menopausal women in Saudi Arabia. 
Funding: No funding sources

Conflict of interest: None declared

Ethical approval: The study was approved by the institutional ethics committee

\section{REFERENCES}

1. McKinney E, Ashwill J, Murray S, James S, Gorrie T, Droske S. Menopause. In: McKinney E, Ashwill J, Murray S, James S, Gorrie T, Droske S. Menopause, eds. Maternal-Child Nursing. St. Louis: Elsevier Science Health Science Division; 2012: 655.

2. Speroff L, Fritz L. The effect of age and menstrual cycle. In: Speroff L, Fritz L, eds. Clinical Gynecologic Endocrinology and Infertility: 7th ed. Philadelphia: Lippincott Williams \& Wilkins; 2005: 613.

3. Bernis C, Reher D. Environmental contexts of menopause in Spain: comparative results from recent research. Menopause. 2007;14(4):777-87.

4. Williams R, Levineb B, Kalilani L, Lewisc J, Clarkd R. Menopause-specific questionnaire assessment in US population-based study shows negative impact on health-related quality of life. Maturitas. 2009;(62):153-9.

5. Lewis V. Under treatment of menopausal symptoms and novel options for comprehensive management. Cur Med Res Opin. 2009;25:2689-98.

6. Thurston R, Joffe H. Vasomotor symptoms and menopause: findings from the study of women's health across the nation. Obstet Gynecol Clin North Am. 2011;38:489-501.

7. Ford K, Sowers M, Crutchfield M, Wilson A, Jannausch M. Longitudinal study of the predictors of prevalence and severity of symptoms commonly associated with menopause. Menopause. 2005;12:308-17.

8. Greenblum C, Meredeth A, Rowe, Neff D, Greenblum S. Midlife women: symptoms associated with menopausal transition and early postmenopause and quality of life. Menopause. 2013 Jan;20(1):22-7.

9. Sallam H, Galal A, Rashed A. Menopause in Egypt: past and present perspectives. Suzanne Mubarak Regional Center Women's Health Devel Egypt. 2006;9(6):421-9.

10. Al-Olayet A, Al-Qahtani I, Al-Essa D, Al-Saleek F, Al-Moutary M. Severity of menopausal symptoms, and knowledge attitude and practices towards menopause among Saudi women. Sci Res Essays. 2010;5(24):4077-9.

11. Heinemann K, Ruebig A, Potthoff P, Schneider HP, Strelow F, Heinemann L et al. The menopause rating scale (MRS) scale: a methodological review. Health Qual Life Outcomes. 2004;2:45.

12. Mishra G, Kuh D. Perceived change in quality of life during the menopause. Soc Sci Med. 2006;62:93102.

13. Catherine A, Meredeth A, Donna F, Jesse S. Midlife women: symptoms associated with menopausal transition and early postmenopausal and quality of life. Menopause. 2012;20(1).

14. Avis N, Assmann S, Kravitz H. Quality of life in diverse groups of midlife women: assessing the influence of menopause, health status and psychosocial and demographic factors. Quality Life Res. 2004;13:933-46.

15. Ham O. Predictors of health-related quality of life among low-income midlife women. West J Nurse Res. 2011; 33: 63-78.

16. Col N, Haskins A, Ewan-Whyte C. Measuring the impact of menopausal symptoms on quality of life: methodological considerations. Menopause. 2009;16:843-5.

17. Nisar N, Ahmed S. Frequency of menopausal symptoms and their impact on the quality of life of women: a hospital based survey. J Pak Med Assoc. 2009;59(11):752-6.

18. Cooper R, Kuh D, Cooper C. Objective measures of physical capability and subsequent health: a systematic review. Age Ageing. 2011 Jan;40(1):1423.

19. Cooper R, Kuh D, Hardy R, Group M, Teams F. Objectively measured physical capability levels and mortality: systematic review and meta-analysis. $\mathrm{Br}$ Med J. 2010;341:c4467.

20. Studenski S, Perera S, Patel K. Gait speed and survival in older adults. J Am Med Assoc. 2011;305:50-8.

21. Lewisa J, Hilditcha J, Wongb C. Further psychometric property development of the menopause-specific quality of life questionnaire and development of a modified version, MENQOLintervention questionnaire. Maturitas. 2005;50:20921.

22. Gehad M, Samia A, Galila S. Effect of menopausal symptoms on women's quality of life in Benha city (Egypt) and Arar city (Kingdom of Saudi Arabia). Med J Cairo Univ. 2010;78(1):319-30.

23. El Sabagh E, Abd Allah E. Menopausal symptoms and the quality of life among pre/post-menopausal women from rural area in Zagazig city. Life Sci J. 2012;9(2):283.

24. Rachel. W, Kristen. L, Kalilani L, Jacqueline L, Richard V. Effects of quetiapine extended release on sleep and quality of life in midlife women with major depressive disorder. Maturitas. 2009;62(2):153-9.

25. Chim H, Tan B, Ang C, Chew E, Chong Y, Saw S. The prevalence of menopausal symptoms in a community in Singapore. Maturitas. 2002;41(4):27582.

26. Jahanfar S, Abdul Rahim A, Shah Reza B, Nor Azura I, Sharifah D, Siti R. Age of Menopause and menopausal symptoms among malaysian women who referred to health clinic in Malaysia. Shiraz EMed J. 2006;7:1-9.

27. Waidyasekera $\mathrm{H}$, Wijewardena $\mathrm{K}$, Lindmark $\mathrm{G}$, Aessen T. Menopausal symptoms and quality of life during the menopausal transition in Sri Lankan women. Menopause. 2009;16:164-70. 
28. Gharaibeh M, Al-Obeisat S, Hattab J. Severity of menopausal symptoms of Jordanian women. Climacteric. 2010;13(4):385-94.

29. Ashrafi M, Ashtiani S, Malekzadeh F, Amirchaghmaghi E, Kashfi F, Eshrati B. Symptoms of natural menopause among Iranian women living in Tehran, Iran. Int J Reprod Med. 2010;8(1):29-32.

30. Rahman S, Zainudin S, Kar Mun V. Assessment of menopausal symptoms using modified menopause rating scale (MRS) among middle age women in Kuching, Sarawak, Malaysia. Asia Pac Family Med. 2010;9:5.

31. Chedraui P, Hidalgo L, Chavez D, Morocho N, Alvarado M, Huc A. Menopausal symptoms and associated risk factors among post-menopausal women screened for the metabolic syndrome. Arch Gynecol Obstet. 2007;(3):161-8.

32. El Shafe K, Al Farsi Y, Al Zadjali N, Al Adawi S, Al Busaidi Z, Al Sha faee M. Menopausal symptoms among healthy, middle-aged Omani women as assessed with the menopause rating scale. Menopause. 2011;(10):1113-9.

33. Kalahroudi M, Mahboubeh T, Sadat Z, Saberi F, Karimian Z. Prevalence and severity of menopausal symptoms and related factors among women 40-60 Years in Kashan, Iran. Nurs Midwifery Stud. 2012:1(2);88-93.

34. Chen Y, Lin S, Wei Y, Gao H, Wu Z. Menopausespecific quality of life satisfaction in community- dwelling menopausal women in China. Gynecol Endocrinol. 2007;23:166-72.

35. Rostami A, Ghofrani Pour F, Ramazan Zadeh F, Kazamnejad A. Effect of health education on knowledge, attitude and quality of life in postmenopausal women. Daneshvar. 2003;11(49):19-23.

36. Lee M, Kim J, Park M, Yang J, Ko YH, Ko S et al. Factors influencing the severity of menopause symptoms in Korean post-menopausal women. J Korean Med Sci. 2010;(5):758-65.

37. Askari F, Basiri M, Torabi S, Ghol S, Mohareri M. Age of natural menopause and the comparison of incidence of its early complications in menopause transition stages in women from Gonabad city. Horizon Med Sci. 2012;17(4):42-8.

38. Lee Y, Kim H. Relationships between menopausal symptoms, depression, and exercise in middle-aged women: a cross-sectional survey. Int J Nurs Stud. 2008;45(12):1816-22.

39. Delavar M, Hajiahmadi M. Factors affecting the age in normal menopause and frequency of menopausal symptoms in northern Iran. Iranian Red Crescent Med J. 2011;13(3):192-8.

DOI: $10.5455 / 2320-1770 . i j \operatorname{cog} 20140906$

Cite this article as: Mohamed HA, Lamadah SM, Zamil LG. Quality of life among menopausal women. Int J Reprod Contracept Obstet Gynecol 2014;3:552-61. 